\title{
Assignments and Grading in Engineering Graphics Courses
}

\author{
http://dx.doi.org/10.3991/ijep.v5i3.4661 \\ P. Kukk ${ }^{1}$ and S. Heikkinen ${ }^{2}$ \\ ${ }^{1}$ Estonian National Defense College, Tartu, Estonia \\ ${ }^{2}$ Aalto University, Espoo, Finland
}

\begin{abstract}
An assignment analysis was carried out according to Bloom's taxonomy for basic and advanced Engineering Graphics courses. Assignments for the first basic course cover the first three levels of Bloom's taxonomy: remembering, understanding and applying, with some elements of creativity. Assignments for the advanced course cover the upper three levels of Bloom's taxonomy: analysing, evaluating and creating. To stimulate student interest in purposeful learning it is essential to strike a balance between student engagement and the courses' learning outcomes as determined by the curriculum. To achieve these goals the following course structure possibilities were analysed: creative elements in assignments; continuous and formative assessment with two-phase feedback; premium grading points; and external motivators. Dependence of the final grade on the prior subject matter knowledge of students was also analysed.
\end{abstract}

Index Terms - engineering graphics, Bloom's taxonomy, assignment, assessment, feedback, prior knowledge

\section{INTRODUCTION}

Over the last few decades the teaching/learning process has been steadily evolving towards being student-oriented (or learning-centred). In addition to the final grades of our courses, close attention is paid to feedback from the learners' perspective. In this context, the lecturer should very carefully design each particular course taking into account the outcomes stipulated by the curriculum, students' preliminary knowledge and their different learning styles. One essential task of higher education is to develop student creativity, their ability to design, construct, compose, write, paint, etc., something new for their own and everyone else's benefit. In order to create something new and interesting, students must first learn to use the tools and common rules of presenting their ideas/data or, in other words, become literate in their specific area of activity. Engineering graphics is a subject which all students learning science and engineering should take. The extent of this learning depends on their particular field of study; prospective engineers should learn it in essentially a wider context so as to be able to compare with other specialities where the ability to read and understand technical drawings is required. In the present paper we analyse two engineering graphics courses taught at higher educational institutions not belonging to the community of technical universities and colleges. Science graduates (physics, chemistry, materials science, etc.) from classic universities should be able to understand technical drawings and also compile (simple) technical drawings and 3D models to express their ideas more precisely to professional engineers.

\section{AIM}

The study aims to use Bloom's taxonomy to analyse the engineering graphics courses taught to cadets at the Estonian National Defence College and to students of the Faculty of Science and Technology at the University of Tartu. The objective of the basic level (3 ECTS) Engineering Graphics I course is to give students knowledge of ISO standards for technical drawings, provide them with practical experience in composing technical drawings using SolidWorks software, and also to develop their three-dimensional imagination and creativity. The objective of the advanced level (3 ECTS) Engineering Graphics II course for University students is to involve them in more complex engineering knowledge such as material processing, design for manufacturing and assembly, and also to give them experience of teamwork while solving engineering/designing problems in threemember teams.

\section{CONSTRUCTIVE ALIGNMENT}

“The '(constructive) alignment' aspect refers to what the teacher does, which is to set up a learning environment that supports the learning activities appropriate to achieving the desired learning outcomes. The key is that the components in the teaching system, especially the teaching methods used and the assessment tasks, are aligned with the learning activities assumed in the intended outcomes. The learner is in a sense 'trapped' and finds it difficult to escape without learning what he or she is intended to learn." [1]

Teacher perspective $\rightarrow$ objectives $\rightarrow$ intended learning outcomes $\rightarrow$ teaching activities $\rightarrow$ assessment

Student perspective $\rightarrow$ assessment $\rightarrow$ learning activities $\rightarrow$ outcomes. [1]

Assessment acts as a way to collect data or evidence. It measures an individual student's competence in different areas of a course. It may include such elements as an exam and homework assignments [2]. Assessment can have more meaning in student learning than anything else. It influences what and how they study [3]. Bloom's original and revised taxonomy $[4,5,6]$ is often used for formulating course outcomes [7], assessment [8], and also for measuring correlations between course outcomes and assessment $[9,10]$.

In the context of the present paper we specify more precisely the assessment aspect of Biggs' constructive alignment from the teacher's perspective, dividing it into 
three subgroups: assessment, assignment and feedback. Assessments are based on the results of students' assignment work which is selected to evaluate/grade learning outcomes. In solving assignments and performing homework tasks, students demonstrate what they have learned. As also concluded by Black and Wiliam: ".....provision of challenging assignments and extensive feedback lead to greater student engagement and higher achievement" [11].

Feedback on the students' individual or team work can have a very powerful influence on learning. Its impact can be positive or negative, meaning that the teacher who provides this feedback plays an important role. Feedback has been mentioned in several studies over the years but there has not been much systematic research on it. Although feedback is one of the main influences on students' studies, it can have different kinds of effects according to type. It is important to give the right feedback at the right time [12].

Timely and individualized, content-related feedback incorporating discussion and guidance gives effective support [13]. Students may also avoid many smaller problems entirely if they receive individual feedback early enough in the course [14]. Feedback has been highly appreciated from the learners' perspective. Effectiveness is important but developmental feedback has received the highest ratings and among students is most strongly associated with effective assessment [15].

\section{ASSIGNMENTS DURING COURSES}

There are three different elective courses: pen and paper courses of descriptive geometry, technical drawing courses (based on Solid Edge) and other different CAD courses in the curricula of Estonian secondary schools. This is the reason why students at the higher education level have very different preliminary knowledge. Our poll among 313 students attending the Engineering Graphics basic courses during 2010 - 2014 showed that $51 \%$ of them do not have any subject-matter preliminary knowledge, $14 \%$ have passed descriptive geometry or technical drawing courses, $7 \%$ have learned different CAD programs, and $16 \%$ have experiences with both technical drawing and CAD. $12 \%$ of the students did not answer to the poll questions. This data determines the framework for conducting the course: it should be on the appropriate level and at the same time gripping for students with different preliminary knowledge.

The assignments selected for homework during the first basic level course should be at a suitable level for firstyear students, i.e., during the period when they need to build confidence in managing their learning. Assignments on the advanced course should be more comprehensive and based on previously acquired knowledge, plus new information they have to learn for solving their assignments. Learning resources consist of a classical textbook for Technical Graphics, for example [16], and SolidWorks (SW) software for compiling 3D models and 2D drawings. All files presented by the lecturer, assignments, e-tests, forums and additional learning materials are collected and stored on the learning management system Moodle and are available to students when needed. During the courses students have to present SW 3D model and 2D drawing files for grading by uploading them to Moodle. There are 7 assignments using SW software (representing $80 \%$ of the final grade), two etests in Moodle (10\%) and two test-papers of descriptive geometry during 45 minutes in the classroom (Fig. 1).

Here students must draw by hand third principal views according to two given views. These two views are chosen in such a manner that there can be several correct solutions for the third view [17]. A sample assignment of descriptive geometry is shown in Fig. 1, where the front and top views of the detail are given and students were asked to draw left side views. Grading was based on the number equal to right solutions minus inaccurate ones. The combination of already proposed solutions from different parts of the model was also excluded from the number of right solutions. In some years, there was a real competition between students in finding more solutions.

We will now look at some short descriptions of SW assignments where $\mathrm{B}$ indicates the basic and $\mathrm{A}$ the advanced course. Assignments from $1 \mathrm{~B}$ to $4 \mathrm{~A}$ should be performed individually, with $5 \mathrm{~A}$ and $6 \mathrm{~A}$ being tackled in teams of three.

Assignments $1 \mathrm{~B}$ and 2B: Remembering/understanding assignments introduces students to using the SW software for building 3D models and compiling 2D drawings based on pictorial drawings. Students have to demonstrate the use of the basic command sets of SW by producing sketches, extruded boss and cut, editing drawings or sections and inserting dimensions.

Assignment 3B: The first assignment with some elements of creativity is based on SW revolves, sweeps and loft commands. Students are asked to design a coffee pot or pitcher with a spout and handle (Fig. 2), or a cup and saucer. Different student groups are given different height-to-diameter ratios or volumes which should be followed with the precision of $10 \%$. These assignments are not precisely formulated and have several different solutions to ensure that students come up with their own designs to meet the requirements.

Assignment 4B: The second assignment on elements of creativity is based on SW's sheet metal design possibilities. These assignments given to students in different years had dissimilar aspects.

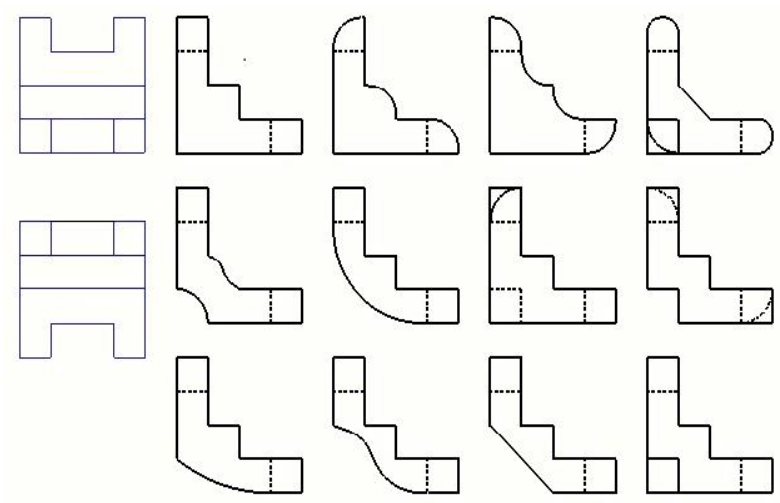

Fig. 1. Test-paper of descriptive geometry with solutions. 


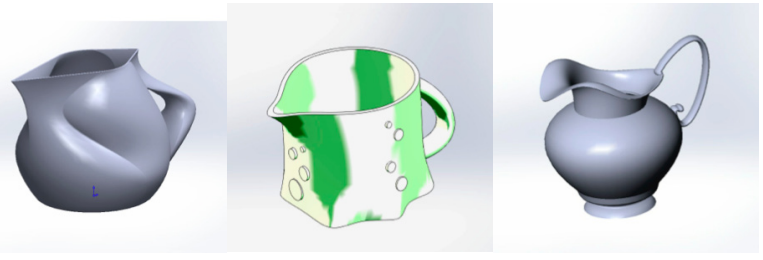

Fig. 2. Pitchers

Their results should meet certain criteria, e.g., constructing a sheet metal bracket to fix a matchbox to a table in such a way that disabled people can remove and light a match with one hand; or being concerned with the economy of material by modelling a sheet metal bracket to fix two matchboxes on a table at a distance of $20 \mathrm{~mm}$ from each other. The grade awarded for this last assignment is proportional to the number of brackets produced and inversely proportional to the amount of scrap material remaining from the large metal sheet after stamping out the maximum number of brackets.

Assignments 5B, 6B, and 7B: For performing precision work, students are asked to construct a $3 \mathrm{D}$ model and $2 \mathrm{D}$ drawing files with sections and dimensions from metal or plastic details (Fig. 3). Details having about $20-25$ dimensions are selected for these assignments.

During the Advanced Engineering Graphics II course the final grade is formed from two distinct parts: students have to present at least $13 \mathrm{SW}$ files to the lecturer for grading $(85 \%)$ and they must also grade each other's teamwork in seminars $(15 \%)$.

Assignment 1A: A revision assignment to go back over the main points of the basic course where students have to construct a 3D model and 2D drawing files according to samples from the SolidWorks CSWA certification test [18].

Assignment 2A: Students have to complete a SW assembly model and drawing files from real details. In solving these assignments students need to analyze details prior to modelling to ensure easier drafting of drawing files.

Assignment 3A: Sample assignments are constructing a set of ring spanners according to certain nut dimensions, constructing a set of gasoline canisters with different volumes, and constructing a set of cog-wheels for a bicycle according to a specified number of cogs. Prior to working with SW, students must perform some data analysis or solve geometrical problems. These assignments give students knowledge of the power of the SW configuration command set for generating completed models according to one specific parameter. With the help of the SW software, students evaluate their data analysis or determined geometrical relations between different dimensions of detail.

Assignment 4A: Creative individual work. Students have to use the SW software to model a kitchen or cheese knife, an axe or a katana.

Assignments 5A and 6A: These are two problem-based creative assignments taken from real life. Three-member teams are formed on a voluntary basis and students must find the solution, choose and execute the overall design themselves. Each team must present their design in class and give reasons why their solution is the best.

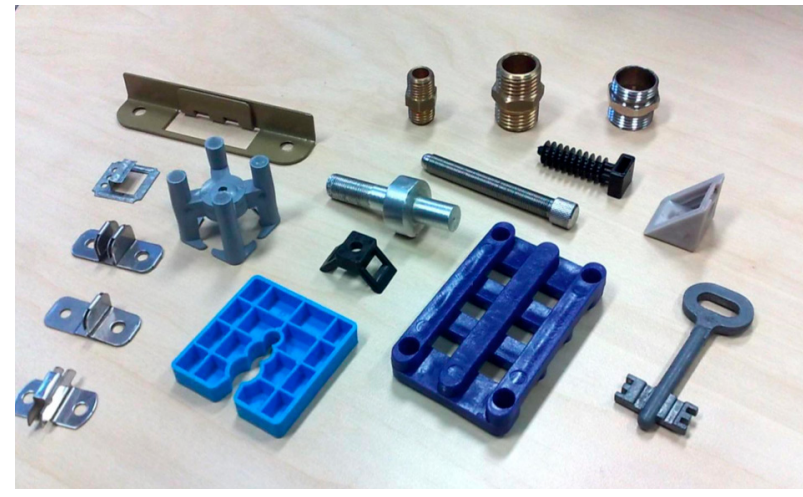

Fig. 3. Details for constructing model and drawing files.

At the end of the seminar groups grade each other's solutions according to three categories: idea, technical execution and presentation. The lecturer summarizes the groups' grades to each other at the end of seminar. The group with the best solution receives maximum points for its presentation and the others get fewer points according to their relative rank of success. In different years students should solve different assignments from real life, being asked to design for example:

a coasting wagon for children's toys with a volume of 40 litres;

a lift for moving statues in a museum;

a four-wheel platform $30 \times 30 \mathrm{~cm}$ for robotronic content (Fig. 4);

a mechanism for moving a car in a small garage perpendicular to the wheels' direction;

a transportable and quickly installable/removable mechanism for moving wheelchairs up and down stairs.

\section{Assesment And FeEdBack During Courses}

A continuous [19] and formative [20] assessment system is used during the courses. The timeline during the semester is chosen so that almost every second Friday evening students upload their assignment solutions into the Moodle learning management system. During the courses students receive two-phase feedback for every assignment: individual, through Moodle, and more generalized feedback on the whole course at the beginning of the next lecture [21]. Both sets of feedback are delivered to students before the deadline of the next assignment. Grading rules (maximum number of available points for assignment and deductions for mistakes) are available for consultation on Moodle.

During the generalized feedback the best assignment solutions are demonstrated to the whole group at the beginning of the lecture, along with the author's name, and the very best of all the solutions receives additional bonus grading points. Also tips on how to make the solution even better are presented by the lecturer or solicited from the audience. Delivering generalized feedback in this way serves two purposes: firstly to reward work well-done, and secondly to attract students' attention to the feedback session. Failed solutions and repeated mistakes are also commented upon, but without revealing their authors to everyone. [22] 


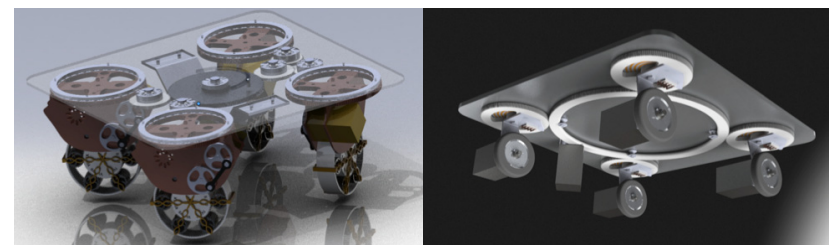

Fig. 4. Platforms for robotronic content.

From the lecturer's point of view, the grading procedures for the SW part and drawing files are rather time-consuming: six to ten assignments per hour. This time spent for grading is of crucial importance as creativity can only be evaluated subjectively by the human mind, and students wish and expect to receive constructive feedback for their assignments [23]. In their own feedback on the course students are asked to answer this statement: "The teacher gave sufficient feedback on the results of my work in completing the course." From 2010 to $201379 \%$ of the 219 students on the basic course fully agreed and $17 \%$ partially agreed with this statement. For the advanced course, over the same period $77 \%$ of the 64 students fully agreed and $20 \%$ partially agreed.

The grading of $3 \mathrm{D}$ models takes into account the choice and use of different SW commands for 3D model file construction and how precisely the model corresponds to the pictorial assignment $(1 \mathrm{~B}, 2 \mathrm{~B}$ or $1 \mathrm{~A})$ or real detail $(5 \mathrm{~A}-7 \mathrm{~A}, 2 \mathrm{~B})$ and students can get maximum 10 points. The grading of $2 \mathrm{D}$ drawings is based on how well they correspond to ISO standards for technical drawings. Here, students are drilled in using the correct scale and layout of views and sections, as well as in the optimal number of views and dimensions. For every drawing students can get a maximum of 15 points and, for example, every missing or excessive dimension is penalized by one point, while the absence of a section incurs a three-point penalty. This penalty scale is available for consultation on Moodle. There have been very few complaints about the rigorous grading of drawings over the years.

The maximum number of points possible for assignments is 200 on the basic and 450 on the advanced Engineering Graphics course. Students achieving at least $90 \%$ receive grade $\mathrm{A}, 80 \% \mathrm{~B}$, and both $\mathrm{A}$ - and $\mathrm{B}$-grade students are then exempt from the final exam. Other students of the basic course must in addition sit the exam, $50 \%$ of their final grade coming from marks for semester assignments and $50 \%$ from exam results.

The exam takes place in a computer lab where students are asked to construct a 3D model and 2D drawing files with sections and dimensions from a metal or plastic detail. The grading rules are the same as for assignments $6 \mathrm{~B}$ and $7 \mathrm{~B}$. During the exam students are allowed to use whatever materials and online tutorials they choose. Setting an exam at the end of the basic course obliges the less capable students to think through the process of compiling SW models and drawing files one more time and, in this context, the exam is a learning process that is not only confined to memorizing material learned during the semester.

The maximum amount of points available for the presentation of the teamwork $5 \mathrm{~A}$ and $6 \mathrm{~A}$ during the seminar is 30 and 40 points respectively. To ensure the equal teamwork participation of students, all members of the team get the equal amount of points for their seminar presentation. This grading rule is introduced to students at the beginning of the course. In addition, each student should also submit for grading three SW 3D and 2D file pairs of both assignments. For these two teamwork assignments the student can get a maximum of 70 points from their mutual grading of seminar presentations, and a maximum of 150 points from a lecturer for six SW file pairs. There is no exam at the end of the advanced course, its final grade being calculated from points collected during the semester.

\section{ANALYSIS}

Assignments for the first basic courses are compiled to cover the first three levels of Bloom's taxonomy: remembering, understanding and applying (Fig. 5). Corresponding assignments cover simple model-building and drawings based on isometric views (assignments 1B and 2B), creating tasks with creative elements for modelling (3B and $4 \mathrm{~B})$, and technical drawing tasks based on real details $(5 \mathrm{~B}-7 \mathrm{~B})$.

Two e-test in the Moodle, where students have to answer questions with multiple-choice answers about ISO standards for technical drawings and most common commands of the SW software, cover two first levels of Bloom's taxonomy. Results of passing these e-tests form $10 \%$ of the final grade.

Assignments of descriptive geometry were introduced to the course to develop students' three-dimensional imagination, creativity and their ability to draw by hand [17]. SW software is a suitable tool to practice the assignments where every change in the shape of threedimensional model is immediately reflected on the classical drawing with three principal views. Grading results show a wide variety of students' abilities to solve these assignments: from thirty to fifty right solutions up to one or two. According to the grading rules of the course the grades for these two descriptive geometry assignments form $15 \%$ of the final grade. Summarizing results of 313 students showed that for 57 of them descriptive geometry grades formed less than $7.5 \%$ of their final grade. There were 4 students who had problems with solving this type of assignments, although they were excellent with SW assignments and got the highest grade for the course. Learning in the computer lab by copying the lecturers' work with SW software remains also on the first two levels of Blooms taxonomy, and this activity is not graded during the course.

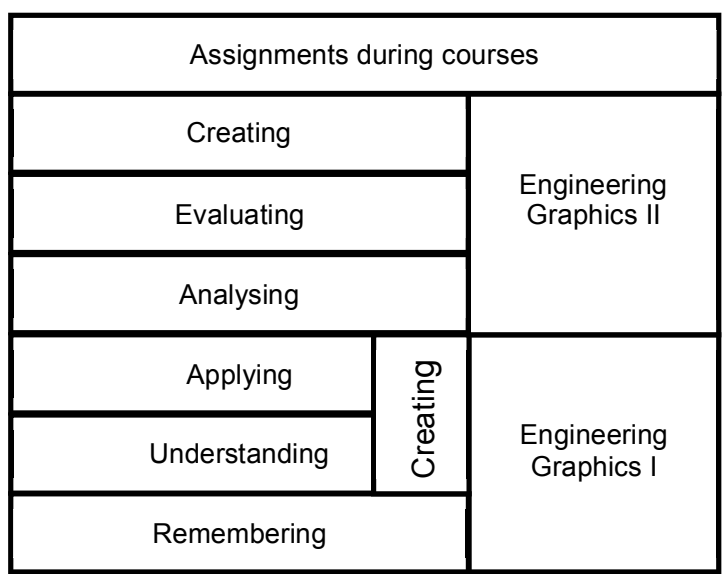

Fig.5. Modified Bloom's taxonomy levels and Engineering Graphics courses 
Solving independent homework assignments corresponds to the third or higher levels of Bloom's taxonomy. Here students have to apply their knowledge acquired during the lab and lectures and depending on the particular assignment to perform some analysis or be creative.

For assignments $3 \mathrm{~B}$ and $4 \mathrm{~A}$ students should only present 3D model SW files for grading. Creative assignments are not overly detailed; they contain some degree of freedom in order to make students take responsibility for their own decisions and find solutions by themselves. During the introduction of the creative assignments, it was essential to stress that there were several correct solutions. To encourage students' creativity the best solutions from previous years were demonstrated and they were asked to make sure their homework was done to the same level or even better!

Giving precision assignments $5 \mathrm{~B}, 6 \mathrm{~B}$, and $7 \mathrm{~B}$ to students at the end of basic course serve the purpose of verifying their ability to apply what they have learned. In everyday life it means that they should be able to create drawings of simple details at the quality level needed for the copying of the details.

Assignments of the advanced Engineering Graphics II course are compiled to cover the upper four levels of Bloom's taxonomy: applying, analysing, evaluating and creating. On the advanced engineering graphics course students must solve assignments covering compiling assemblies (2A), linking model-building with mathematical analysis (3A), creating creative modelbuilding (4A), and innovative problem-based teamwork (5A and 6A). It is essential that students also understand this general principle, more precisely why their course assignments are presented in this particular order. First of all they have to acquire enough literacy in compiling engineering models and drawings - the first three levels of Bloom's taxonomy. This is followed by additional learning and practice - Bloom's taxonomy levels up to evaluation. After they have acquired sufficient knowledge in these areas we can then introduce creating and creativity. Discussion about different levels of creativity in the learning process is given in the paper referenced at footnote [24]. During the learning process students wish to achieve measureable results faster. In order to maintain their commitment to purposeful, deep learning it is essential that the process be interesting and challenging for them [11]. For the abovementioned reasons, creative tasks were added to the content of courses based on the lower levels of Bloom's taxonomy, thus also allowing those students to demonstrate their creativity.

For providing feedback on the course itself, students answer the following: "The teacher taught the course excellently (sparked interest, comprehensive presentation, engaging, etc.)". This statement may be viewed as a measure of constructive alignment from the students' perspective. From 2010 to $201363.4 \%$ of the 219 students on the basic course fully agreed and $31 \%$ partially agreed with this statement. For the advanced course, over the same period $64 \%$ of the 64 students fully agreed and $30 \%$ partially agreed.

Practical assignments with thinking are a very important part of engineering education because only $31 \%$ of female students and $17 \%$ of male students learn by feeling or watching (Table 1). [26]
TABLE I.

KOLB'S LEARNING STYLES WHEN TEACHING SCIENCE

\begin{tabular}{|l|c|l|l|l|l|}
\hline & N & Feeling & Watching & Thinking & Doing \\
\hline $\begin{array}{l}\text { Female } \\
\text { students }\end{array}$ & 76 & $5 \%$ & $26 \%$ & $18 \%$ & $50 \%$ \\
\hline $\begin{array}{l}\text { Male } \\
\text { students }\end{array}$ & 58 & $0 \%$ & $17 \%$ & $38 \%$ & $45 \%$ \\
\hline
\end{tabular}

This is the reason why only homework is graded during these courses - students have to think and do things by themselves.

SW software generates 2D drawings from 3D models. For compiling correct drawings it is essential that 3D models be perfectly oriented in the SW 3D space. This analysis should be performed before starting the 3D modelling process.

In almost all cases students should present both their 3D model and 2D drawing SW files for grading. In their feedback on the course students indicated that modelbuilding is an interesting task. To foster student commitment and introduce the element of competition, the lecturer awards bonus points for building models using fewer SW feature commands. In this way, the lecturer is promoting thinking and analysis before implementing.

Teamwork assignments $5 \mathrm{~A}$ and $6 \mathrm{~A}$ at the end of the advanced course were the most exciting for students. Students must find attractive solutions for the proposed assignments. To showcase their solutions, some groups created separate PowerPoint files, SW animations and videos to demonstrate the working principles. A professional engineer was involved to give feedback on teamwork results. Making presentations and defending ideas under competitive conditions is also the kind of knowledge and experience required in today's world.

After completing $50 \%$ of the advanced course students receive a free voucher from the teacher to sit the threehour on-line CSWA certification test [18]. The pass rate for this voluntary certification was $84 \%$. Passing this test gives students a certificate whose level is known worldwide, their names appear in on-line database [25] and possession of this certificate is also worthy of note in a student's Curriculum Vitae.

The maximum number of points for assignments on the basic EG course was 200 plus bonus points for well-done work. Awarded bonus points formed up to $20 \%$ of the maximum points of the particular assignment. During the years $2010-201445 \%$ of the students got bonus points. The best students collected 15 bonus points and the average for students who got the bonus was 6.0 points. Table 2 summarises the dependence of the collected points on students' prior knowledge. One grade level equals to twenty points.

Experiences with both technical drawing and CAD result in average level (179 points) only one grade higher compared to the students who did not answered to the poll questions (159 points). Prior knowledge facilitates solving assignments of descriptive geometry ( 22.5 points). Here is the largest difference (24\%) with students who do not have any prior subject matter knowledge (17.6 points). 
TABLE 2.

DEPENDENCE OF THE AMOUNT OF COLLECTED POINTS ON THE PRIOR KNOWLEDGE OF 313 STUDENTS

\begin{tabular}{|c|c|c|c|}
\hline \multirow[b]{2}{*}{ Prior knowledge } & \multicolumn{3}{|c|}{ Average collected points } \\
\hline & $\begin{array}{c}\text { Assignments } \\
\text { of descriptive } \\
\text { geometry }\end{array}$ & $\begin{array}{c}\text { Assignments } \\
\text { with SW } \\
\text { software }\end{array}$ & $\begin{array}{l}\text { Whole } \\
\text { basic } \\
\text { course }\end{array}$ \\
\hline $\begin{array}{l}\text { Experiences with } \\
\text { both technical } \\
\text { drawing and CAD }\end{array}$ & 22.5 & 134 & 179 \\
\hline $\begin{array}{l}\text { Different CAD } \\
\text { programs }\end{array}$ & 19.6 & 135 & 175 \\
\hline $\begin{array}{l}\text { Descriptive } \\
\text { geometry or } \\
\text { technical drawing } \\
\text { courses }\end{array}$ & 20.1 & 131 & 172 \\
\hline $\begin{array}{l}\text { Without any prior } \\
\text { subject-matter } \\
\text { knowledge }\end{array}$ & 17.6 & 126 & 163 \\
\hline $\begin{array}{l}\text { Not answered to } \\
\text { the poll questions. }\end{array}$ & 19.2 & 122 & 159 \\
\hline
\end{tabular}

Comparison of average points collected for assignments done with SW software shows that there is only $3 \%$ (4 points) difference between three groups of students, those who have prior experience with both technical drawing and $\mathrm{CAD}$, or knowledge of different $\mathrm{CAD}$ programs, or those who have knowledge of descriptive geometry. The data in Table 2 allows concluding that method of conducting the basic engineering graphics course in the above described way is suitable for students with different prior knowledge. Final results of 38 students who did not answer the poll question about their prior knowledge were very divergent. Six of them got the highest and seven the lowest grade, one of them got " $\mathrm{B}$ " due to 10 bonus points.

"Please regularly solve homework assignments and present your work for grading by the required date." - this is one message taken from student feedback, given as advice to students who will be taking the course in future years. In his longitudinal investigation Juha Jaako also found that continuous assessment during the semester increases the pass rate and, from the student's point of view, grade formation is transparent [27].

\section{CONCLUSION}

Engineering graphics is not in itself a very interesting subject to learn. There is a large amount of precise ISO and ANSI standards, amongst others, which must be followed in order to complete technical drawings. To stimulate student interest in purposeful learning and balance this with the courses' learning outcomes, the following elements were introduced into the teaching/learning process:

assignments aligned according to Bloom's taxonomy;

creative elements in assignments;

continuous and formative assessment;

two-phase feedback - individual and generalized;

bonus points in grading procedures to reward particularly impressive homework;

lecturer support for and focus on those elements of the course which were interesting to students; drilling on ISO standards does not dominate the course; "external" motivators. On the basic course a $3 \mathrm{D}$ printout for the best solution of design assignment $3 \mathrm{~B}$ was given as a gift to the author. On the advanced course the feedback for teamwork assignments $5 \mathrm{~A}$ and $6 \mathrm{~A}$ was given by a professional engineer, a conducted tour to modern metal workshop was organized for students, and they had an opportunity to gain an official CSWA certificate.

Summative feedback was positive for the Engineering Graphics courses taught in the ways described above. In recent years grades given by students ranged from 4.5 to 4.8 on a 5 -point scale. Student feedback indicated that they enjoyed the diversity of assignments and tasks in which they had to employ creative approaches, and in the advanced course the most exciting elements were said to be problem-based teamwork seminars and assignments for which students themselves had to find the overall design of the models.

The authors would like to thank mrs. Epp Leete for her help and critical reading of the paper.

\section{REFERENCES}

[1] J. Biggs, Aligning teaching for constructing learning, 31 March, 2014, [Online] Available:

http://www.heacademy.ac.uk/assets/documents/resources/database id477_aligning_teaching_for_constructing_learning.pdf.

[2] B.M. Olds, B.M Moskar and R.L. Miller, "Assessment in engineering education: Evolution, approaches and future collaborations," Journal of Engineering Education, vol.1, pp. 1325, January 2005. http://dx.doi.org/10.1002/j.21689830.2005.tb00826.x

[3] D. Boud, Developing Student Autonomy in Learning, London: Kogan Page, 1998.

[4] B.S. Bloom, Taxonomy of Educational Objectives, Handbook I: The Cognitive Domain. New York: David McKay Co Inc, 1956.

[5] B.S. Bloom, Taxonomy of Educational Objectives. Boston, MA: Allyn and Bacon, 1984.

[6] D.R. Krathwohl, "A revision of Bloom's taxonomy: An overview;" Theory into Practice, vol. 41, pp. 212-218, Autumn 2002. http://dx.doi.org/10.1207/s15430421tip4104 2

[7] G.L. Fiegel, "Incorporating learning outcomes into an introductory geotechnical engineering course," European Journal of Engineering Education, vol. 38, pp. 238-253, June 2013. http://dx.doi.org/10.1080/03043797.2013.794200

[8] M. Burrow, H. Evdorides, B. Hallam and H. Freer-Hewish, "Developing formative assessments for postgraduate students in engineering," European Journal of Engineering Education, vol. 30, pp. 255-263, February 2005. http://dx.doi.org/10.1080/ 03043790500087563

[9] M. Valcke, B.De Wever, C. Zhu and C. Deed, "Supporting active cognitive processing in collaborative groups: The potential of Bloom's taxonomy as a labelling tool," Internet and Higher Education, vol. 12, pp. 165-172, December 2009. http://dx.doi.org/10.1016/j.iheduc.2009.08.003

[10] V.A. Jideani and I.A. Jideani, "Alignment of assessment objectives with instructional objectives using revised Bloom's taxonomy-The case for food science and technology education," Journal of Food Science Education, vol 11, pp. 34-42, July 2012. http://dx.doi.org/10.1111/j.1541-4329.2012.00141.x

[11] P. Black and D. Wiliam, "Assessment and classroom learning," Assessment in Education: Principles, Policy \& Practice, vol. 5, pp. 7-74 March 1998. http://dx.doi.org/10.1080/0969595980050102

[12] J. Hattie and H. Timperley, "The power of feedback," Review of Educational Research, vol. 77, pp. 81-112, March 2007. http://dx.doi.org/10.3102/003465430298487

[13] E.J. Burge, "Learning in computer conferenced contexts, the Learner's Perspective," Journal of Distance Education, vol. 9, pp. 19-43, 1994. 
PAPER

ASSIGNMENTS AND GRADING IN ENGINEERING GRAPHICS COURSES

[14] M. Limniou and M. Smith, "Teachers' and students' perspectives on teaching and learning through virtual learning environments," European Journal on Engineering Education, vol. 35, pp. 645-653, December 2010. http://dx.doi.org/10.1080/03043797.2010.505279

[15] A. Lizzio and K. Wilson, "Feedback on assessment: Students' perceptions of quality and effectiveness," Assessment \& Evaluation in Higher Education, vol.33, pp. 263-275 June 2008. http://dx.doi.org/10.1080/02602930701292548

[16] E.T. Boyer, F.D. Meyers, F.M.Jr Croft, M.J. Miller and J.T. Demel, Technical Graphics, New York: John Wiley \& Sons Inc, 1991.

[17] P. Kukk and M. Pandis, "Engineering curriculum and Torrance tests of creative thinking," in Experience and Reflection on Active Learning in Engineering Education, Proc. of 7th ALE International Workshop, G. Moore and A. Hernandez, Eds. Toulouse: INSA Toulouse, pp. 323 - 328, 2007.

[18] SolidWorks certification, 31 March, 2014, [Online] Available: https://solidworks.com/sw/support/mcad-certificationprograms.htm.

[19] S. Myllymäki, "Incorporation of continuous student assessment into lectures in engineering education," European Journal of Engineering Education, vol. 38, pp. 385-393, April 2013. http://dx.doi.org/10.1080/03043797.2013.780010

[20] O.A.B. Hassan, "Learning theories and assessment methodologies - an engineering educational perspective," European Journal of Engineering Education, vol 36, pp. 327-339, July 2011. http://dx.doi.org/10.1080/03043797.2011.591486

[21] P. Kukk and T. Marandi, "Creativity in engineering education," in Engineering Education - the Priority for Global Development, F. Flückiger, R. Ruprecht and T. Rüütmann, Eds. Proceedings of the 35th International IGIP Symposium in cooperation with IEEE / ASEE / SEFI], Tallinn, Tallinn Technical University Press, pp. $463-468,2006$.

[22] S. Heikkinen and P. Kukk, "Effects of extra marks in course evaluation in engineering education," Journal of Teaching and Education, 3(3), 131 - 135, 2014.
[23] P. Kukk and L. Sõord, "Thinking "Out of the box" in courses of engineering education," In: Engineering Graphics BALTGRAF11, R. Mägi, Ed. Tallinn: Tallinn Technical University Press, pp. $41-45,2011$.

[24] C. Zhou, "Integrating creativity training into problem and projectbased learning curriculum in engineering education," European Journal of Engineering Education, vol. 37, pp. 488-499, October 2012. http://dx.doi.org/10.1080/03043797.2012.714357

[25] SolidWorks ${ }^{\circledR}$ Certification Center, 31 March, 2014, [Online] Available: https://solidworks.virtualtester.com/\#userdir_button.

[26] D.A. Kolb, Learning Style Inventory, version 3, Boston: The Hay Group, 1999.

[27] J. Jaako, "Controlling the didactic relation: a case in process engineering education," European Journal of Engineering Education, December 2013 [Online], http://dx.doi.org/10.1080/03043797.2013.867315

\section{AUTHORS}

P. Kukk is with the Chair of Natural and Exact Sciences, Estonian National Defense College, 51013 Tartu, Estonia (e-mail: peeter.kukk@ut.ee). The Engineering Graphics courses is conducted by Peeter Kukk for the students of the Faculty of Science and Technology at the University of Tartu and for the cadets of the Estonian National Defense College.

S. Heikkinen is with the School of Electrical Engineering, Aalto University, 00076 Espoo, Finland (email: sanna.heikkinen@, aalto.fi).

This article is an extended and modified version of a paper presented at the EDUCON2015 conference held at Tallinn University of Technology, Tallinn, Estonia, 18-20 March 2015. Submitted 27 April 2015. Published as resubmitted by the authors 25 June 2015. 